\title{
Erratum to: Impact of temperature on the biosynthesis of cytotoxically active carbamidocyclophanes A-E in Nostoc sp. CAVN10
}

\author{
Michael Preisitsch $^{1} \cdot$ Ha Thi Ngoc Bui ${ }^{1,2} \cdot$ Christian Bäcker $^{1} \cdot$ Sabine Mundt $^{1}$
}

Published online: 12 February 2016

(C) Springer Science+Business Media Dordrecht 2016

Erratum to: J Appl Phycol

DOI 10.1007/s10811-015-0657-7

Figure 2 was incorrectly typeset and posted online. The correct image is shown below and was also rectified in the download version of the article.

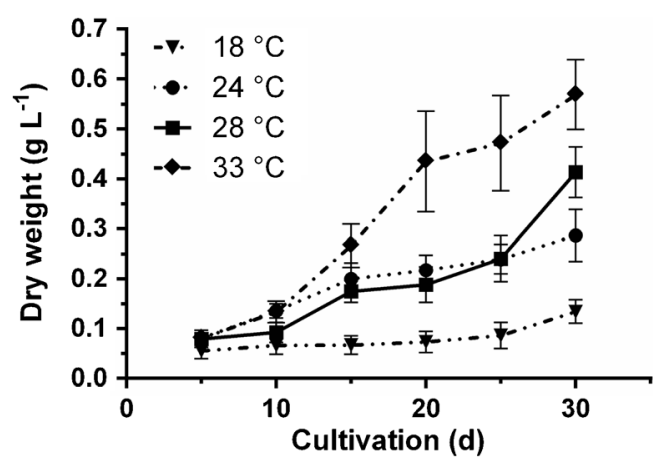

The online version of the original article can be found at http://dx.doi.org/ 10.1007/s10811-015-0657-7.

Michael Preisitsch

michael.preisitsch@uni-greifswald.de

1 Department of Pharmaceutical Biology, Institute of Pharmacy, Ernst-Moritz-Arndt-University, Friedrich-Ludwig-Jahn Straße 17, 17489 Greifswald, Germany

2 Public Health Center Laboratory, Hanoi School of Public Health, 138 Ginag Võ, Hanoi, Vietnam 